\title{
A família e suas demandas para o autocuidado apoiado no contexto da doença onco- hematológica
}

\author{
The family and its requirements for supported self-care in the context of onco-hematology disease \\ La familia y sus demandas para el autocuidado apoyado en el contexto de la enfermedad onco- \\ hematológica
}

Recebido: 31/01/2021 | Revisado: 05/02/2021 | Aceito: 10/02/2021 | Publicado: 16/02/2021

Thiago Ferreira de Freitas

ORCID: https://orcid.org/0000-0001-5882-3024

Universidade Federal Fluminense, Brasil

E-mail: thiago.eeap@gmail.com

Sonia Regina de Souza

ORCID: https://orcid.org/0000-0001-7981-0038 Universidade Federal do Estado do Rio de Janeiro, Brasil

E-mail: soniasilvio0@gmail.com

Fátima Helena do Espírito Santo

ORCID: https://orcid.org/0000-0003-4611-5586 Universidade Federal Fluminense, Brasil E-mail: fatahelens@gmail.com

Florence Romijn Tocantins

ORCID: https://orcid.org/0000-0002-1968-8701

Universidade Federal do Estado do Rio de Janeiro, Brasil

E-mail: florenceromijn@ hotmail.com

Teresinha de Jesus Espírito Santo da Silva

ORCID: https://orcid.org/0000-0003-0194-7469

Universidade Federal do Estado do Rio de Janeiro, Brasil

E-mail: helenarj@terra.com.br

Leila Leontina do Couto

ORCID: https://orcid.org/0000-0002-8948-5045 Universidade Federal Fluminense, Brasil

E-mail: leila_leontina@hotmail.com

\begin{abstract}
Resumo
A atenção ao cliente onco-hematológico deve ser planejada em um continuum que considere o seu sistema familiar como elemento importante para a gestão da condição crônica de saúde. Assim, este estudo visa identificar as demandas de autocuidado apoiado presentes no sistema familiar do cliente onco-hematológico. Trata-se de estudo qualitativo realizado através de entrevistas semiestruturadas com quatro sistemas familiares de clientes oncohematológicos de um hospital universitário a partir de um roteiro elaborado com questões referentes à categoria funcional do Modelo Calgary de Avaliação da Família e ao item de avaliação da metodologia dos 5 "A" do Manual de Autocuidado Apoiado. Após análise e interpretação dos dados obteve-se uma unidade temática com três subunidades, as quais foram orientadas pelos domínios e classes de NANDA para identificação do domínio afetado e seu respectivo foco de atenção: 1 - tomada de decisão a partir do sistema familiar; 2 - (re)organização e envolvimento familiar após o impacto do diagnóstico; e 3 - bem-estar e corresponsabilização no controle da saúde. Conclui-se que a família se reorganiza em prol da restauração da saúde de seu familiar, requerendo um cuidado que envolva aconselhamento, apoio e promoção da saúde; apontando à necessidade de ampliação da utilização dos referenciais deste estudo na assistência de enfermagem à família do cliente onco-hematológico.
\end{abstract}

Palavras-chave: Enfermagem; Família; Doença crônica; Oncologia.

\begin{abstract}
Care for onco-hematological clients should be planned in a continuum that considers their family system as an important element for the management of chronic health conditions. Thus, this study aims to identify the demands for supported self-care present in the family system of the onco-hematological client. This is a qualitative study carried out through semi-structured interviews with four family systems of onco-hematological clients of a university hospital based on a script elaborated with questions regarding the functional category of the Calgary Model of Family Assessment and the evaluation item of the 5 "A" methodology of the Supported Self-Care Manual. After analyzing and interpreting the data, a thematic unit with three subunits was obtained, which were guided by the NANDA domains and classes to identify the affected domain and its respective focus of attention: 1 - decision making from the
\end{abstract}


family system; 2 - (re) organization and family involvement after the impact of the diagnosis; and 3 - well-being and co-responsibility for health control. It is concluded that the family reorganizes itself in order to restore the health of its relative, requiring care that involves counseling, support and health promotion; pointing to the need to expand the use of the references of this study in nursing care for the family of the onco-hematological client.

Keywords: Nursery; Family; Chronic disease; Oncology.

\section{Resumen}

La atención al cliente onco-hematológico debe planificarse en un continuo que considere su sistema familiar como un elemento importante para el manejo de la condición crónica de salud. Así, este estudio tiene como objetivo identificar las demandas de autocuidado con apoyo presentes en el sistema familiar del cliente onco-hematológico. Se trata de un estudio cualitativo realizado a través de entrevistas semiestructuradas con cuatro sistemas familiares de clientes oncohematológicos de un hospital universitario basado en un guión elaborado con preguntas sobre la categoría funcional del Modelo Calgary de Evaluación Familiar y el ítem de evaluación del 5 Metodología "A" del Manual de autocuidado asistido. Luego del análisis e interpretación de datos, se obtuvo una unidad temática con tres subunidades, las cuales fueron guiadas por los dominios y clases NANDA para identificar el dominio afectado y su respectivo foco de atención: 1 - toma de decisiones desde el sistema familiar; 2 - (re) organización e implicación familiar tras el impacto del diagnóstico; y 3 - bienestar y corresponsabilidad del control sanitario. Se concluye que la familia se reorganiza para restaurar la salud de su familiar, requiriendo cuidados que involucran consejería, apoyo y promoción de la salud; apuntando a la necesidad de ampliar el uso de las referencias de este estudio en el cuidado de enfermería para la familia del cliente onco-hematológico.

Palabras clave: Enfermería; Familia; Enfermedad crónica; Oncología.

\section{Introdução}

A realidade das condições crônicas de saúde é um problema cada vez mais evidente e discutido no cenário mundial de atenção à saúde. Neste contexto, o câncer é uma das doenças mais incidentes no mundo com 18 milhões de casos novos em 2018, sendo a primeira ou segunda principal causa de morte prematura (30-69 anos) em 134 de 183 países e a segunda causa de morte no Brasil (World Health Organization, 2020) (Inca, 2019).

Se por um lado, estes valores expressivos contribuam para o desenvolvimento de políticas públicas de prevenção e promoção da saúde no contexto da doença oncológica, por outro, não são capazes de traduzir a real experiência/vivência da pessoa com câncer e sua família frente a esta condição crônica de saúde.

Isto porque, diante das inúmeras repercussões promovidas pelo impacto do diagnóstico do câncer, as famílias remodelam seus projetos de vida e incluem um continuum de cuidado que não visa somente o manejo clínico da doença, mas também o seu enfrentamento e a restauração de seu equilíbrio familiar, já que a doença é considerada um assunto de família (Ferraza et al, 2016) (Morais et al, 2019) (Wright \& Leahey, 2012).

Como principal vínculo de apoio e cuidado no processo de adoecimento, a eficácia dos cuidados de saúde estabelecidos pela família obtém melhores resultados quando o foco é dado sobre ela e não somente ao membro doente. Desta forma, faz-se necessário que os profissionais de saúde, em especial o enfermeiro, as compreendam como unidades de cuidado e utilizem uma abordagem que considerem suas características sistêmicas e a dinamicidade das suas estruturas e funções frente à experiência familiar do câncer (Feijó et al, 2019) (Santos, 2012).

A partir disso, entende-se que este contexto requisitará das famílias o desenvolvimento de novas competências e habilidades, técnicas ou não, frente à variedade de comportamentos de autocuidado utilizados pelas pessoas com câncer e às necessidades de apoio e de intervenção advindas da (con)vivência com a doença oncológica (Budhwani et al, 2019).

Desta forma, o autocuidado apoiado (um dos pilares do "Chronic Care Model”) surge como importante ferramenta de cuidado neste contexto, pois visa empoderar as pessoas a gerirem sua própria condição de saúde. Para isso, enfatiza o seu papel central no cuidado por meio da informação, motivação e capacitação, permitindo que adquiram habilidades e confiança, tomem decisões, utilizem recurso e estabeleçam parcerias de cuidado (família e profissionais) para a (re)construção de sua saúde (OPAS, 2015). 
Frente a isso, acredita-se que o presente artigo possibilite a ampliação das discussões acerca das experiências de famílias frente ao adoecimento pelo câncer ao utilizar uma abordagem que a coloca como foco de atenção a partir de seu potencial sistêmico. Além disso, direciona-se a um grupo pouco investigado na literatura científica nacional e internacional (adultos com doenças onco-hematológicas) uma vez que a concepção da díade paciente/pessoa-família é clara na população infantil e as investigações envolvem o contexto dos tumores sólidos, com destaque para os de mama (Lacerda et al, 2020).

Portanto, este artigo tem como objetivo identificar as demandas de autocuidado apoiado presentes no sistema familiar do cliente onco-hematológico, uma vez que tais aspectos viabilizam compreender o seu contexto, organização e o modo de enfrentamento dos problemas advindos do contexto de cuidado familiar, pois reconhece a família como espaço de suporte e manutenção à vida.

\section{Metodologia}

Trata-se de estudo de abordagem qualitativa e de caráter exploratório realizado na unidade clínica de hematologia de um hospital universitário no município do Rio de Janeiro, pertencente ao Sistema Único de Saúde, classificado como unidade de alta complexidade e referência em oncologia.

Os participantes do estudo compreenderam quatro sistemas familiares compostos por quatro clientes com diagnóstico de doença onco-hematológica que estiveram internados na referida unidade durante o período de coleta de dados (marçomaio/2015) e quatro respectivos familiares indicados pelos mesmos.

Para critério de inclusão, participaram os clientes com idade mínima de 18 anos, que tinham conhecimento do diagnóstico de doença onco-hematológica e que estivessem internados na referida unidade durante o período de coleta de dados, e os familiares com idade superior a 18 anos e quem o cliente referisse como membro de sua família.

A exclusão foi considerada para clientes em primeira internação e sem diagnóstico definido e que não possuíam condições cognitivas e/ou clínicas para participar do estudo.

Os dados foram obtidos através de entrevistas semiestruturadas realizadas em local reservado e confortável, com cada sistema familiar, ou seja, cliente e familiar indicado.

A decisão da escolha de participação de apenas um familiar deve-se ao fato de que a soma de cada experiência representa um recorte do todo independente do número de pessoas a serem entrevistadas, além de representar a escolha de alguém com um com um laço afetivo e significativo para o cliente, corroborando com a definição de família descrita por Wright e Leahey (2012, p. 55) de que "família são quem seus membros dizem que são".

As entrevistas foram guiadas pelo instrumento de entrevista construído pelo presente autor com base nas dimensões estrutural (identificação dos sistemas familiares) e funcional (identificação das demandas) do MCAF (Wright \& Leahey, 2012). Assim, foram coletadas informações sobre cada membro (idade, escolaridade, ocupação, religião, grau de parentesco dentre outros), tendo como ponto de partida os participantes deste estudo, acrescentando-se os demais membros do núcleo familiar.

Além destes, o instrumento também foi constituído de perguntas abertas referentes ao primeiro dos cinco A's da metodologia do autocuidado apoiado (Avaliação) (OPAS, 2015), a fim de se avaliar os conhecimentos sobre a doença, o seu impacto no sistema familiar e quais foram cuidados/comportamentos adotados pelas famílias para a manutenção da saúde.

Os conteúdos das entrevistas foram gravados em mídia digital, sendo posteriormente transcritos na íntegra para viabilizar a análise dos dados. Ressalta-se que o presente artigo representa um recorte da dissertação de mestrado "O cliente onco-hematológico e sua família: Subsídios para o autocuidado apoiado em oncologia" (Freitas, 2015) e se detém apenas a dimensão funcional do MCAF em razão deste possibilitar a compreensão da relação entre os membros familiares, das 
modificações na vida familiar e da adoção de posturas proativas para manutenção da saúde de seus membros e de todo o sistema familiar.

As informações sobre a dimensão estrutural utilizadas neste artigo são para apresentação e caracterização dos sistemas familiares uma vez que no projeto original, a representação da estrutura familiar e de seus relacionamentos é feita através do genograma e do ecomapa, respectivamente.

Os dados foram submetidos à técnica de análise temática (Minayo, 2010), sendo identificados 17 temas, que após agrupamentos e reagrupamentos, possibilitaram a construção de uma unidade temática composta por três subunidades: 1 Tomada de decisão a partir do sistema familiar; 2 - (Re)organização e envolvimento familiar após o diagnóstico; e 3 - Bemestar e corresponsabilização no controle da saúde.

Cabe destacar que este processo foi orientado pelos treze domínios e respectivas classes da taxonomia II da NANDA International Inc (NANDA International, 2013), conduzindo assim à identificação de quatro domínios relacionados às subunidades temáticas: Percepção/Cognição (sub. 1); Enfrentamento e Tolerância ao Estresse (sub. 2); Papéis e Relacionamentos (sub. 2); e Promoção da Saúde (sub. 3), além da identificação dos respectivos focos de intervenção (aconselhamento, apoio e promoção).

O estudo atendeu aos princípios éticos estabelecidos pela resolução nº66/12 do Conselho Nacional de Saúde acerca de pesquisas envolvendo seres humanos, sendo os participantes identificados por nomes fictícios auto atribuídos, assinatura do Termo de Consentimento Livre e Esclarecido, e aprovação dos Comitês de Ética em Pesquisa (UNIRIO - CAAE: 39378814.4.0000.5285; UFF - CAAE: 39378814.4.3001.5243).

\section{Resultados e Discussão}

\section{Caracterizando e conhecendo os sistemas familiares}

Os clientes possuíam características bem heterogêneas: três do sexo masculino e apenas um do sexo feminino; idades entre 19 e 61 anos; quanto ao estado civil, dois tinham união estável, um era casado e o outro solteiro; dois tinham o ensino médio completo, e os demais com ensino fundamental e médio incompletos; três não exerciam atividades laborais por conta da doença; possuíam diagnósticos distintos e datados entre março e dezembro de 2014. Tais singularidades possibilitaram compreender as histórias de vida e da doença de cada cliente e sua família de forma singular.

Todos os quatro familiares indicados eram do sexo feminino, sendo três com vínculo de esposa e uma de mãe (também casada), os quais estavam como acompanhantes na enfermaria durante grande parte das internações. Estas tinham entre 21 e 57 anos; três com ensino fundamental incompleto e uma com superior completo; uma era comerciante, outra dona de casa e as demais não trabalhavam em razão da doença do familiar.

Cada paciente e seu respectivo familiar caracterizavam-se como um sistema familiar e se apresentaram com característica nuclear (composta por pais e filhos que residem no mesmo domicílio).

Além das informações sobre os participantes, outras foram relevantes para conhecer os demais membros da família nuclear assim como da família extensa e quem era considerado família pelos participantes conforme quadro abaixo (Quadro 1). 
Quadro 1 - Composição e características dos sistemas familiares dos clientes onco-hematológicos. Rio de Janeiro, 2020.

\begin{tabular}{|c|c|c|c|c|c|c|c|c|}
\hline $\begin{array}{c}\text { Sistema } \\
\text { Familiar } \\
\text { (SF) }\end{array}$ & $\begin{array}{c}\text { Cliente } \\
\text { Diagnóstico }\end{array}$ & $\begin{array}{c}\text { Data do } \\
\text { Diagnóstico }\end{array}$ & $\begin{array}{l}\text { Familiar } \\
\text { indicado }\end{array}$ & $\begin{array}{l}\text { Nucleo } \\
\text { Familiar }\end{array}$ & $\begin{array}{c}\text { Familia } \\
\text { considerada } \\
\text { pelos } \\
\text { entrevistados }\end{array}$ & $\begin{array}{c}\text { Ocupaçăo } \\
\text { Cliente/F amiliar }\end{array}$ & Familia de origem & $\begin{array}{l}\text { Familia de } \\
\text { relacionamento } \\
\text { anterior }\end{array}$ \\
\hline SF-1 & $\begin{array}{l}\text { Roberto } \\
25 \text { ancos } \\
\text { Leucemis } \\
\text { Promielocitica } \\
\text { Aouda }\end{array}$ & $\begin{array}{l}\text { Outubro } \\
\text { de } 2014\end{array}$ & $\begin{array}{l}\text { Adriana } \\
\text { (esposs) } \\
21 \text { anon }\end{array}$ & $\begin{array}{l}\text { Ocasale } \\
\text { dois filhos }\end{array}$ & Filhos & $\begin{array}{l}\text { Roberto } \\
\text { pedreiro } \\
\text { Adriana } \\
\text { dona decasa }\end{array}$ & $\begin{array}{l}\text { Roberto - máe, } \\
\text { pez e rma } \\
\text { Adriana - măe, } \\
\text { pai e irmbło }\end{array}$ & nåo he \\
\hline SF-2 & $\begin{array}{l}\text { Caroline } \\
19 \text { ances } \\
\text { Lirloma de Burkat }\end{array}$ & $\begin{array}{l}\text { Nowembro } \\
\text { de } 2014\end{array}$ & $\begin{array}{l}\text { Suzana } \\
\text { (máe) } \\
42 \text { anos }\end{array}$ & $\begin{array}{c}\text { Carcline e ces } \\
\text { pars }\end{array}$ & $\begin{array}{l}\text { Mse } \\
\text { Pail } \\
\text { Irmato }\end{array}$ & $\begin{array}{l}\text { Carosine } \\
\text { Suzana } \\
\text { năo trabaltham }\end{array}$ & $\begin{array}{c}\text { Caroline - máe, } \\
\text { pal e irmiso } \\
\text { suzana - máe e } \\
\text { pai (falecidoes) e } 5 \\
\text { irmáos }\end{array}$ & năo ha \\
\hline $\mathrm{SF}-3$ & $\begin{array}{l}\text { MonAmour } \\
54 \text { Bnos } \\
\text { Meloma Milliplo }\end{array}$ & $\begin{array}{l}\text { Marcyo } \\
\text { de } 2014\end{array}$ & $\begin{array}{l}\text { Cocota } \\
\text { (esposa) } \\
59 \text { ancs }\end{array}$ & $\begin{array}{c}\text { Ociasale } \\
\text { ums } \\
\text { firna/ernegda }\end{array}$ & Fitha/enteede & $\begin{array}{l}\text { Mon Amour } \\
\text { pedreiro } \\
\text { Cocota } \\
\text { dona de case }\end{array}$ & $\begin{array}{l}\text { Mon Amour - mâe } \\
\text { e pai (falecidos) e } \\
4 \text { imáas } \\
\text { Cocota - mbe o pas } \\
\text { (falecidos) } \theta 9 \\
\text { irmáos }\end{array}$ & $\begin{array}{c}\text { 2Ex-esposas +3 } \\
\text { finos } \\
\text { Ex-manido }+4 \\
\text { filhos }\end{array}$ \\
\hline $5 F-4$ & $\begin{array}{c}\text { Jose } \\
\text { 61 anos } \\
\text { Linfoma Nato- } \\
\text { Hodgkon }\end{array}$ & $\begin{array}{c}\text { Degzembro } \\
\text { de } 2014\end{array}$ & $\begin{array}{l}\text { Mana } \\
\text { (eaposa) } \\
57 \text { anos }\end{array}$ & $\begin{array}{c}\text { Nova } \\
\text { Friburgo-o } \\
\text { cseal } \\
\text { Niterói - o } \\
\text { casal e firns }\end{array}$ & $\begin{array}{l}\text { Pai } \\
\text { Mae } \\
\text { Filhas }\end{array}$ & $\begin{array}{l}\text { Jose e Maria } \\
\text { comerciantes }\end{array}$ & 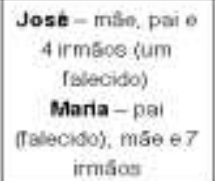 & ngo ha \\
\hline
\end{tabular}

Fonte: Freitas (2015)

\section{O sistema familiar no contexto da doença onco-hematológica}

A presente unidade temática reflete aspectos importantes que permitiram conhecer em profundidade como a família pode ser considerada unidade de cuidado e como o autocuidado apoiado se faz presente neste contexto. Assim, foram identificadas três demandas presentes no contexto da condição crônica de saúde de origem onco-hematológica, os domínios de NANDA afetados e seus respectivos focos de atenção.

Subunidade temática I - Tomada de decisão a partir do sistema familiar

As famílias que convivem no contexto de uma condição crônica de saúde sabem melhor do que os demais sobre a doença e as necessidades que são por ela impostas mediante a forma em que a percebem a doença.

Desta forma, relacionada ao domínio de NANDA Percepção/Cognição e ao primeiro dos 5 A's (Avaliação) do Manual de Autocuidado Apoiado, esta demanda reflete o que cada família sabe sobre a doença e como a (re)interpreta, mediante movimentos de busca de informações e as suas crenças relacionadas à expectativa de cura e confiança no tratamento.

Essa (re)interpretação deve-se ao fato dos sistemas familiares conhecerem o "rótulo" do diagnóstico, mas explicarem as causas a partir de relações que fazem sentido para eles, reconhecendo a gravidade da doença e a necessidade de um tratamento intenso.

Eu sei muito pouco sobre a doença. Porque quando eu soube sobre a doença, eu nem quis muito saber sobre ela.

Talvez medo, insegurança. De sofrer entendeu? (SF-1 Roberto).

Primeiro, por que eu não sei nada sobre a doença também... Porque não é uma doença fácil. É uma doença grave. (SF-1 Adriana).

Porque até aí eu não sabia, não tinha ideia do que era... Vai continuar pro resto da vida com esse tratamento. (SF-3 Mon Amour) 
Eu sei que o câncer que eu tenho é agressivo e eu preciso de um tratamento intenso, por isso que eu tenho que ficar internada um período para fazer o ciclo né? (SF-2 Caroline).

Cara, eu não sei muito sobre a doença. Porque eu tô tendo ela, não. (SF-4 José).

Frente a isso, as famílias buscam informações através da equipe de saúde, dos próprios familiares ou da internet para suprirem essa "necessidade" de informações, muitas vezes estabelecendo um limite até onde e o que é necessário saber, para assim compreenderem sobre a situação de saúde, a doença e o tratamento.

Assim, eu procuro não pesquisar muito porque eu já li muita coisa não saudável. Então eu prefiro acreditar mais no pessoal daqui (hospital), no que o médico diz. Então, é o que eu sei. (SF-2 Caroline)

Ah, eu pesquisei algumas coisas... Então o médico passa pra ela (Caroline) e vocês também (enfermeiros) falam e ensinam alguma coisa pra ela, e ela pra gente ir aprendendo. (SF-2 Suzana)

Então, quando chegou na nossa mão o primeiro exame, as meninas iam no computador e eu também fui na internet. Por fim, eu parei porque eu falei assim: "Epa. Isso ai são termos médicos" Você começa a ler, imaginar coisas. (SF4 Maria)

Assim, o conhecimento destas famílias apresenta um caráter limitado e permeado por sentimentos negativos que exprimem incertezas como medo, insegurança e gravidade da doença, mas essenciais para que compreendam as repercussões da doença no estado de saúde do cliente onco-hematológico e se mobilizem para o seu enfrentamento.

No entanto, muitas famílias ainda silenciam o diagnóstico como modo de proteção do familiar doente, não sabem lidar com suas repercussões, não buscam informações ou não receberam orientações adequadas. Com isso, estabelece-se na prática de cuidado em oncologia uma dicotomia entre o que as famílias devem e querem/precisam efetivamente saber sobre a doença, fazendo com que o medo e a insegurança estabeleçam limites na aquisição de novos conhecimentos e entendimento dessa experiência pelo sistema familiar (Herr et al, 2013) (Neves, et al, 2017).

Desta forma, destaca-se que para a tomada de decisão, informação e educação são peças fundamentais que auxiliam no manejo clinico da condição crônica e visam à aquisição de novas habilidades para se aprender a conhecer e aprender a fazer no gerenciamento da condição crônica de saúde (Brasil, 2014).

Como parte deste processo, compreender as crenças relativas ao diagnóstico, a cura e ao tratamento destas famílias são relevantes já que estão intimamente relacionadas ao modo como as pessoas se comportam e refletem "o projeto sobre o qual construímos nossas vidas e as entremeamos com as vidas dos outros” (Wright \& Leahey, 2012, p.144)

Assim, motivados pelas crenças de confiança no tratamento e esperança de cura, as famílias projetam um caminho de superação de obstáculos que está vinculado aos benefícios do tratamento e à busca pela recuperação da saúde do seu familiar (Ferrazza et al, 2016).

Assim, que o médico veio falar pra mim que a doença dele é a mais curável né? ... E estamos aí na fé de que tudo vai dar certo. Mas o que o médico fala é isso, que tem cura que tudo vai dar certo. (SF-1 Adriana)

Por isso que eu acredito, que aqui ele só vai melhorar, melhorar e em nome de Jesus ele vai ficar bom. Nada pra Deus é impossível. Em creio nisso porque eu já vi ele (Mon Amour) muito ruim. A vista do que eu vejo agora, ele está bom. Então por isso que minha fé cada dia aumenta. (SF-3 Cocota) 
Percebe-se assim que esse sentimento de esperança, otimismo e força espiritual são importantes ferramentas de enfrentamento de situações adversas que impulsionam as famílias a projetar um futuro positivo, estimulando e adicionando fé no sucesso do vivenciar uma condição crônica e contribuindo para a melhoria qualidade de vida relacionada à saúde do familiar doente, sobretudo, nas dimensões de conforto, bem-estar e relacionamento com os outros (Menezes et al, 2018).

Deste modo, a tomada de decisão adotada por esses sistemas familiares evidencia a sua (pre)ocupação e participação efetiva já no inicio desse novo contexto de saúde/doença/tratamento a partir da busca dos conhecimentos necessários para compreender a situação atual a fim de que se tornem proativas e possam optar qual caminho seguir para apoiar o autocuidado do cliente onco-hematológico.

Subunidade temática II - (Re)organização e envolvimento familiar após o impacto do diagnóstico

A partir do impacto do diagnóstico, o fluxo de energia dos sistemas familiares direciona-se a movimentos que garantam/restaurem o seu equilíbrio. Assim, (re)arranjos nas relações familiares e fortalecimento de vínculos são estabelecidos. Tal movimento relaciona-se ao domínio de NANDA Enfrentamento e tolerância ao estresse, e Papéis e relacionamento, tendo o foco de atenção no apoio.

O choque emocional e a "surpresa" exemplificam como o diagnóstico da doença onco-hematológica foi recebido pelas famílias deste estudo, já que o câncer é passível de ocorrer em outras famílias e não na sua. Os sentimentos desestabilizadores advindos deste momento como o susto, a preocupação e a sensação de impotência revelam as diversas facetas do impacto sofrido pelas famílias ao aceitar essa nova realidade e ao mesmo tempo ser fonte de apoio para o familiar doente (Lima et al, 2016) (Ferrazza et al, 2016) (Morais et al, 2019).

Mas assim, foi um susto pra gente né? ... Assim, que a gente sempre vê acontecendo na família dos outros. Nunca na nossa. Quando aconteceu, pra mim foi um susto...Deixa a gente com a cabeça... entendeu? Mas, é difícil. É difícil. (SF-1 Adriana)

Foi um choque. Ninguém esperava. A gente sempre acha que vai acontecer na família dos outros, mas não na nossa. (SF-2 Caroline)

A descoberta foi até um pouco... Assim, na hora que o médico fala dá um choque assim em você. Porque espera assim, uma pneumonia passada, um monte de coisas você fica pensando né? Mas nunca você chega assim, é isso. (SF-4 Maria)

Deste modo, os sistemas familiares suscitaram alterações significativas no seu modo de viver com o intuito de oferecer o suporte adequado ao seu membro doente. Assim, adaptações de rotinas e de trabalho, sobretudo referentes ao aspecto financeiro devido ao afastamento do trabalho por limitações da doença ou do regime de tratamento exemplificam as (re)organizações estabelecidas por estas famílias (Figueiredo et al, 2017).

A gente só teve que se adaptar um pouco assim, meu pai, por exemplo, teve que se adaptar ao trabalho, aos horários pra não perder o trabalho e ficar comigo às vezes. (SF-2 Caroline)

Mas a gente se limitou em tudo. Em fazer dívidas. E os passeios, cortamos. (SF-3 Cocota)

A nossa filha tomou conta (comércio da família) porque ela sabe que a gente precisava. E a gente falou: Nós vamos precisar de você ". Porque as outras duas aqui, não tinha como tirar do trabalho. (SF-4 Maria) 
Diante da situação de doença, os papéis e relacionamentos estabelecidos por estas famílias também foram (re)estruturados e fortalecidos em todos os espaços de convívio, principalmente com o seu núcleo familiar, minimizando conflitos e ampliando as relações saudáveis (Bard \& Cano, 2018). Isto ocorre porque "o núcleo familiar continua sendo de incontestável importância no equilíbrio do homem, mantendo-o ligado a laços fortes que se fazem evidentes nos momentos de dificuldades" (Visentin \& Lenardt, 2010, p.491)

Mas graças a Deus a gente tá junto. Tem que estar junto nas horas boas e nas horas ruins também. É isso né? (SF-1 Adriana)

Na verdade era muito desunido e com o problema da Caroline, quando ela foi diagnosticada com câncer, todo mundo se juntou entendeu? A preocupação aumentou e tudo sumiu. Então a gente se junta. Não tem mais tanta briga. (SF-2 Suzana)

Mais cuidados com ele. Muito mais. Da família inteira... Os cuidados com ele foram redobrados. Em relação a todo mundo. (SF-4 Maria)

Com isso, o apoio intra e extra familiar recebidos se traduzem em estar junto para o que for necessário, promovendo a saúde e amenizando o sofrimento provocado pela doença, o que se reflete positivamente na funcionalidade familiar e tem efeito moderador nos sintomas depressivos e na qualidade de vida de pacientes oncológicos (Teston et al, 2017) (Sette \& Capitão, 2018) (Lacerda et al, 2020).

Desta forma, as famílias deste estudo se caracterizam como unidades de cuidado ao invés de contexto de cuidado, visto seus movimentos de organização e enfrentamento para atender as demandas de cuidado que se direcionam à sobrevivência do familiar doente. No entanto, cabe destacar que a utilização da abordagem sistêmica às famílias também permite conhecer as vulnerabilidades pessoais de cada membro familiar, reconhecendo a coesão e continuidade que um estabelece com o outro, e assim, promover modificações em toda a família a partir de intervenções sistêmicas.

\section{Subunidade temática III - Bem-estar e corresponsabilização no controle da saúde}

Como atitudes de apoio ao membro doente, as famílias destacam os cuidados que consideram necessários para o controle da saúde, garantia de continuidade do tratamento e, sobretudo, a proteção do seu familiar. Essas atitudes atingem dimensões física, ambiental, social e emocional, que estão baseadas nos valores e crenças compartilhados por cada família e se relacionam ao domínio de NANDA Promoção/Controle da saúde, tendo como foco de atenção a promoção.

Deste modo, a preocupação com a dimensão física direcionou-se à manutenção de uma alimentação adequada que se estendia a todo sistema familiar, com preocupação na higiene e seleção dos alimentos, e a realização de atividades de repouso ou de distração como o uso da televisão ou ligações telefônicas.

Os cuidados com a alimentação. Não que antes não tivesse, mas hoje é muito mais criteriosa. Tipo, lavar as coisas muito bem lavadas, e aí certas coisas evitar, tipo coisas pesadas. (SF-2 Carolina)

E a alimentação também tentou mudar pra ser mais nutritiva e mais saudável. Menos gordura, tempero adequado e todo mundo se adequou... Bastante legume, bastante verdura. (SF-4 Maria)

Acredito que é isso. Mais repouso. (SF-1 Roberto) 
Eu fico em casa e vejo televisão, rezo o terço, fico no telefone. (SF-4 José)

Para estas famílias, a alimentação perpassa o ponto de vista nutricional e atinge as dimensões simbólicas e subjetivas do ato de nutrir o seu familiar doente. Assim, esta preocupação se intensifica uma vez que às características da doença, as especificidades do tratamento e seus efeitos colaterais (imunossupressão, náuseas, vômitos, inapetência e etc) promovem modificações no comportamento alimentar de pessoas em tratamento quimioterápico, com consequente perda de peso e impacto no prognóstico da doença (Capelari \& Cenni, 2018).

Outra preocupação identificada foi a limitação imposta pelas famílias na realização das atividades diárias pelos clientes onco-hematológicos. Mesmo percebida em forma de descontentamento, tanto pelo posicionamento das famílias quanto pelas limitações da doença, essas denotavam uma resignação frente a esta nova condição de viver.

Ela (mãe) não me deixa fazer nada. Absolutamente nada. Nenhum esforço físico, nada. (SF-2 Carolina)

Vejo minha televisão, que sempre faço quando tô em casa e só isso. Minha vida vai ser só isso... Ela (esposa) faz os afazeres de casa e eu fico, felizmente ou infelizmente, fico vendo TV.... Então por isso que eu já sei, me conformei... Jamais eu vou ser aquele que eu era. (SF-3 Mon Amour)

Este comportamento protetor visa à conservação da energia do seu familiar, uma vez que o domínio físico de qualidade de vida é o mais afetado negativamente em estudo com pessoas com câncer hematológico (leucemia mieloide crônica), estando relacionado aos fatores energia e fadiga, atividade da vida cotidiana, mobilidade e capacidade de trabalho dentro outros (Albuquerque, Ximenes \& Diniz, 2019).

O cuidado com a higiene pessoal e do ambiente (zelo com a limpeza e a organização) também se fez presente nas manifestações do cuidado e visavam um ambiente isento ou com o mínimo de riscos capazes de comprometer a saúde do familiar doente. Este comportamento se traduz em práticas que são apreendidas no universo hospitalar e são transferidas para a dinâmica familiar.

A gente tá sempre evitando ter poeira lá em casa. Sempre mantendo meu quarto limpinho... Eu sei que no caso de limpeza, minha mãe cuidou disso quando eu estava internada... Fez uma limpeza geral. Arrumou meu quarto e deixou o mais limpo possível. (SF-2 Caroline)

Olha, o próprio ambiente mudou né? Porque a mãe dele dispôs o quarto dela pra que eu ficasse com ele. Um quarto já com banheirinho, pra ninguém entendeu? ...A minha cunhada espalhou várias garrafinhas de álcool gel pela casa, da cozinha até o quarto. (SF-4 Maria)

Um elemento considerado importante para o controle da saúde e garantia do tratamento foi o isolamento social. Embora seja visto como aspecto negativo do tratamento oncológico, o mesmo não foi observado nas famílias deste estudo, pois compreendem que algumas precauções se fazem necessárias, mas não impedem a sociabilidade deste cliente.

O principal é ter pouco contato com as pessoas... (SF-1 Roberto)

E como agora eu tô passando por uma fase que eu não posso ter muito contato com muitas pessoas, a gente está evitando um pouco... (SF-2 Caroline) 
Porque além de ser uma pessoa muito conhecida, param na rua conversam com ele, com outro, e às vezes a com a imunidade muito baixa, não pode. (SF-4 Maria)

A partir disso, foi estabelecida uma rede de proteção emocional ao familiar doente através da "seleção" do que ou de quem é benéfico ou não. As brigas familiares, situações geradoras de estresse e preocupação, e visitas inoportunas e pessimistas são consideradas prejudiciais à saúde desse membro. Com isso, a família estabelece limites e regras nas suas relações que ditam o seu funcionamento como novos hábitos e papéis a fim que o familiar doente não seja prejudicado por outros problemas além dos quais já necessita lidar (Melo et al, 2012).

Não passar estresse pra ele, entendeu? Não ter briga entre família. (SF-1 Adriana)

Porque a família... tem alguns familiares que passam muita preocupação a respeito de estresse, briga, entendeu? E eu procuro me afastar disso, ainda mais nesse momento. Por isso que eu prefiro ficar mais afastado com a minha família. (SF-1 Roberto)

Utilizando seus recursos, as famílias se mobilizaram para construir seu próprio modo de cuidado, adotando novas atitudes em saúde que buscavam a manutenção da saúde dos seus membros e de todo o sistema familiar e o enfrentamento desta doença (Morais et al, 2019). Deste modo, percebeu-se que estas famílias consideram saúde como sinônimo de bem-estar e têm suas práticas de cuidado baseadas no amor, carinho e proteção que são oriundos das suas crenças, valores e hábitos.

\section{Considerações Finais}

A partir deste estudo, observa-se que a utilização da abordagem sistêmica à família e dos referenciais do autocuidado apoiado permitiram ouvir essas famílias em profundidade, compreender suas singularidades e identificar suas demandas para o autocuidado apoiado no manejo da doença oncológica, já que ambos enfatizam a coesão e continuidade que o cliente oncohematológico e sua família estabelecem entre si.

Esta compreensão é ratificada nos genogramas e ecomapas estabelecidos por cada família e que estão presentes na totalidade deste estudo; os quais se estruturam como importantes ferramentas de cuidado a ser utilizado por enfermeiros que trabalham com famílias em qualquer cenário de atuação.

Para estas famílias, o cliente onco-hematológico não é considerado um fardo. Pelo contrário, as demandas identificadas e seus respectivos focos de atenção (tomada de decisão a partir do sistema familiar - aconselhamento; (re)organização e envolvimento familiar após o impacto do diagnóstico - apoio; e bem-estar e corresponsabilização no controle da saúde - promoção), revelam a importância de tal membro para a saúde e equilíbrio dessas famílias, além de as caracterizarem como ambientes de cuidado e manutenção da vida.

Assim, esse estudo apresenta uma nova faceta acerca da investigação em famílias uma vez que buscou compreender a experiência a partir de forma integrada ao considerar a dinamicidade do sistema familiar e não apenas de um lado. Além disso, aponta aspectos positivos desta experiência já que as famílias não apresentaram sentimento de desesperança, projetando perspectivas positivas para o futuro do familiar doente, adquirindo novas competências (empoderamento no cuidar) e remodelando seus projetos de vida.

Ressalta-se que o número de participantes foi um fator de preocupação no início deste estudo. No entanto, amparado pelos referenciais teóricos utilizados, a qualidade das informações obtidas pelas entrevistas permitiu explorar em profundidade a realidade das famílias, atendendo ao objeto, objetivos e desenho metodológico do estudo. 
Por fim, tendo em vista o caráter de avaliação deste estudo, aponta-se a possibilidade de utilização de seus referenciais em outros contextos e cenários, a fim de que auxilie os profissionais de saúde, em especial o enfermeiro, na promoção de novas práticas de cuidado e fomente futuras pesquisas que abordem modelos teóricos e terapêuticos acerca da real importância da inclusão da família no contexto do cuidado à pessoa com doença onco-hematológica.

\section{Referências}

Albuquerque, P. M. S; Ximenes, D. I. J., \& Diniz, M. F. F. M. (2015). Avaliação da Qualidade de Vida de Portadores de Leucemia Mieloide Crônica em João Pessoa-PB no período de 2015 a 2016. Revista Eletrônica Acervo Saúde, 11(14), e1248. https://acervomais.com.br/index.php/saude/article/view/1248/704. https://doi.org/10.25248/reas.e1248.2019

Brasil. Ministério da Saúde. (2014). Estratégias para o cuidado da pessoa com doença crônica. Brasília: Ministério da Saúde. http://www.189.28.128.100/dab/docs/portaldab/publicacoes/caderno_35.pdf.

Bard, B. A, \& Cano, D. S. (2018). O papel da rede social de apoio no tratamento de adultos com câncer. Mudanças - Psicologia da Saúde, 26(1), 23-33. https://www.metodista.br/revistas/revistas-metodista/index.php/MUD/article/view/8742/6351. https://doi.org/10.15603/2176-1019/mud.v26n1p23-33

Budhwani, S., Wodchis, W. P., Zimmermann, C., Moineddin, R. \& Howell, D. (2019). Self-management, self-management support needs and interventions in advanced cancer: a scoping review. BMJ Supportive \& Palliative Care, 9, 12-25. https://spcare.bmj.com/content/9/1/12.long. 10.1136/bmjspcare-2018001529

Capelari, P; \& Ceni, G. C. (2018). Comportamento alimentar e perfil nutricional de pacientes oncológicos em tratamento quimioterápico. Demetra, 13(1), 223240. https://www.e-publicacoes.uerj.br/index.php/demetra/article/view/30309. https://doi.org/10.12957/demetra.2018.30309

Feijó, A. M., Santo, B. P., Schwartz, E., Fernandes, A. J. F., Lutz, T., \& Linck, C. L. (2019). Família: principal vínculo apoiador do homem com câncer. Enfermagem Revista, 21(2), 1-14. http://periodicos.pucminas.br/index.php/enfermagemrevista/article/view/18819.

Ferraza, A., Muniz, R. M., Pinto, B. K., Viegas, A. C., \& Matos, M. R. (2016). A sobrevivência ao câncer na perspectiva da família. Rev enferm UFPE on line, 10(3), 1022-8. https://periodicos.ufpe.br/revistas/revistaenfermagem/article/viewFile/11054/12469. https://doi.org/10.5205/reuol.8702-76273-4SM.1003201611

Figueiredo, T. (2017). Como posso ajudar? Sentimentos e experiências do familiar cuidador de pacientes oncológicos. ABCS Health Sci., 42(1), 34-39. https://webcache.googleusercontent.com/search?q=cache:H3A-31PQyk4J:https://www.portalnepas.org.br/abcshs/article/view/947/759+\&cd=5\&hl=ptBR\&ct=clnk\&gl=br. 10.7322/abcshs.v42i1.947

Freitas, T. F. (2015). O cliente onco-hematológico e sua família: subsídios para o autocuidado apoiado em oncologia (Dissertação de Mestrado). Universidade Federal do Estado do Rio de Janeiro, Escola de Enfermagem Alfredo Pinto, Rio de Janeiro, RJ, Brasil.

Herr, G. E., Kolankiewicz, A. C. B., Berlezi, E. M., Gomes, J. S., Magnago, T. S. B. S., Rosanelli, C. P., Loro, M. M. (2013). Avaliação de Conhecimentos acerca da Doença Oncológica e Práticas de Cuidado com a Saúde. Revista Brasileira de Cancerologia, 59(1), 33-41. https://rbc.inca.gov.br/site/arquivos/n_59/v01/pdf/06-avaliacao-de-conhecimentos-acerca-da-doenca-oncologica-e-praticas-de-cuidado-com-a-saude.pdf

Instituto Nacional de Câncer José Alencar Gomes da Silva - INCA. (2019). Estimativa 2020: incidência de câncer no Brasil. Instituto Nacional de Câncer José Alencar Gomes da Silva. Coordenação de Prevenção e Vigilância. - Rio de Janeiro: INCA. https://www.inca.gov.br/sites/ufu.sti.inca.local/files//media/document//estimativa-2020-incidencia-de-cancer-no-brasil.pdf

Lacerda, C. S., Balbino, C. M., Sá, S. P. C., Silvino, Z. R., Silva Júnior, P. F., Gomes, E. N. F. \& Joaquim, F. L. (2020). Confrontation of women with breast cancer. Research, Society and Development, 9(7):1-18. e165974018.

Lima, S. F., Silva, R. G. M., Silva, V. S. C., Pasklan, A. N. P., Reis, L. M. C. B., \& Silva, U. C. (2016). Representações sociais sobre o câncer entre familiares de pacientes em tratamento oncológico. REME Rev Min Enferm, 20: e967. http://www.reme.org.br/artigo/detalhes/1103.

Melo, M. C. B., Barros, E. N., Campello, M. C. V. A., Ferreira, L. Q. L., Rocha, L. L. C., Silva, C. I. M. G., \& Santos, N. T. F. (2012). O funcionamento familiar do paciente com câncer. Psicologia em Revista, 18(1), 78-89. http://www.pepsic.bvsalud.org/pdf/per/v18n1/v18n1a07.pdf. https://dx.doi.org/10.5752/P.1678-9563.2012v18n1p73

Menezes, R. R., Kameo, S. Y., Valença, T. S., Mocó, G. A. A., \& Santos, J. M. J. (2018). Qualidade de Vida Relacionada à Saúde e Espiritualidade em Pessoas com Câncer. Revista Brasileira de Cancerologia, 64(1), 9-17. http://www1.inca.gov.br/rbc/n_64/v01/pdf/01-qualidade-de-vida-relacionada-a-saudee-espiritualidade-em-pessoas-com-cancer.pdf

Minayo, M. C. S. (Org.). (2010). Pesquisa Social: teoria, método e criatividade. (29a ed.), Vozes.

Morais, E. S., Muniz, R. M., Viegas, A. C., Cardoso, D. H., Santos, B. P., \& Pinto, B. K. (2019). Vivência da família na sobrevivência ao câncer: entre esperança de cura e medo da recidiva. Rev Enferm Atenção Saúde, 8(1), 39-50. http://seer.uftm.edu.br/revistaeletronica/index.php/enfer/article/view/3344/pdf. https://doi.org/10.18554/reas.v8i1.3344

Nanda International. (2015). Diagnósticos de enfermagem da NANDA: definições e classificação 2015-2017. (10a ed.), Artmed.

Neves, F. B., Noguez, P. T., Guimarães, S. R. L., Muniz, R. M., \& Pinto, B. K. (2017). Decisões contraditórias: motivos que levam o familiar cuidador a omitir o diagnóstico de câncer. Rev Enferm $\quad$ UFPE https://www.periodicos.ufpe.br/revistas/revistaenfermagem/article/viewFile/11978/14530 
Research, Society and Development, v. 10, n. 2, e29110212527, 2021

(CC BY 4.0) | ISSN 2525-3409 | DOI: http://dx.doi.org/10.33448/rsd-v10i2.12527

Organização Pan-Americana da Saúde. (2015). Cuidados inovadores para condições crônicas: organização e prestação de atenção de alta qualidade às doenças crônicas não transmissíveis nas Américas. Washington, DC: OPAS. http://www.iris.paho.org/xmlui/handle/123456789/18640.

Santos, M. L. V. A. (2012). Abordagem sistêmica do cuidado à família: impacto no desempenho profissional do enfermeiro (Tese de Doutorado). Escola Superior de Enfermagem de Lisboa, Universidade de Lisboa, Lisboa. http://repositorio.ul.pt/bitstream/10451/6979/1/ulsd_re1182_td.pdf

Sette, C. P., \& Capitão, C. G. (2018). Efeito moderador do suporte social em pacientes oncológicos. Psicologia, Saúde \& Doenças, 19(2), 265-277. http://www.scielo.mec.pt/pdf/psd/v19n2/v19n2a09.pdf. https://dx.doi.org/10.15309/18psd190209

Teston, E. F., Silva, A. C. P, \& Marcon, S. S. (2017). Percepção de pacientes oncogeriátricos sobre a funcionalidade familiar. REME Rev Min Enferm, 21:e1032. http://www.reme.org.br/artigo/detalhes/1168

Visentin, A., \& Lenardt, M. H. (2010). O itinerário terapêutico: história oral de idosos com câncer. Acta Paul Enferm, 23 (4), 486-92. http://www.scielo.br/pdf/ape/v23n4/07.pdf

World Health Organization (WHO). (2020). International Agency for Research on cancer. World Cancer report: Cancer research for cancer prevention. Lyon: Internacional Agency for Research on cancer. https://www.iccp-portal.org/system/files/resources/IARC\%20World\%20Cancer\%20Report\%202020.pdf

Wright, L. M., \& Leahey, M. (2012). Enfermeiras e famílias: Guia para avaliação e intervenção na família. (5a ed.), Roca. 